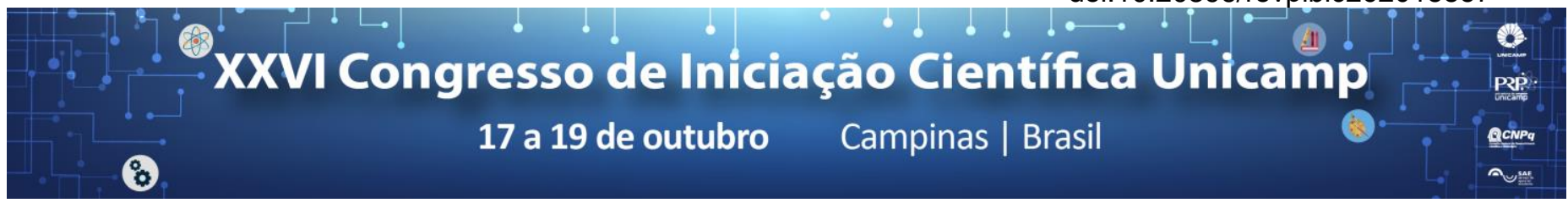

\title{
Estudo do Comportamento do Agrotóxico Piriproxifeno na Presença de Óxido de Grafeno em Água Utilizando Daphnia similis como biosensor
}

\section{Livia Rodrigues Sabino*, Josiane A. S. Vendemiatti, Patrícia Prediger}

\section{Resumo}

Este trabalho relata o estudo do comportamento do agrotóxico piriproxifeno em água na presença e ausência do nanomaterial óxido de grafeno, usando Daphnia similis como biosensor.

\section{Palavras-chave:}

Agrotóxico, nanomaterial, biosensor.

\section{Introdução}

O agrotóxico piriproxifeno ganhou destaque nos noticiários pois, além de ser utilizado em diversas culturas alimentícias, o seu uso foi considerado, pela OMS, seguro no combate ao mosquito Aedes aegypti, transmissor de várias doenças ${ }^{1}$. Com isso, há a necessidade de verificar o comportamento desse agrotóxico no ecossistema aquático, utilizando uma tecnologia barata e de alta eficiência, entre elas, o nanomaterial óxido de grafeno (GO). Além da capacidade do GO e seus derivados em adsorver contaminantes presentes na água, ${ }^{2}$ este nanomaterial pode se comportar como surfactante. O GO possui uma natureza anfifílica, possuindo caráter hidrofílico e hidrofóbico, podendo assim, o GO interagir com compostos orgânicos e com água, reduzindo, então, a energia interfacial. ${ }^{3}$ Assim, o objetivo deste trabalho foi estudar o comportamento do GO frente ao agrotóxico piriproxifeno utilizando Daphnia similis como biosensor.

\section{Resultados e Discussão}

Inicialmente, o piriproxifeno foi purificado através de coluna cromatográfica a partir do composto comercial Tiger 100. Em seguida, testes de toxicidade com os biosensores em água foram realizados a partir da adição direta de uma solução-estoque de piriproxifeno preparada em DMSO. Com base nos dados obtidos foi possível, estimar o valor da concentração responsável por 10\% da mortalidade dos biossensores (Concentração Efetiva, CE10), cujo valor foi $140 \mu \mathrm{g} / \mathrm{L}$.

Em seguida, foram realizados testes em béqueres contendo água onde a solução-estoque de piriproxifeno foi adicionada na presença e na ausência do GO, conforme mostrado na Figura 1.

Figura 1. Esquema dos testes de toxicidade.

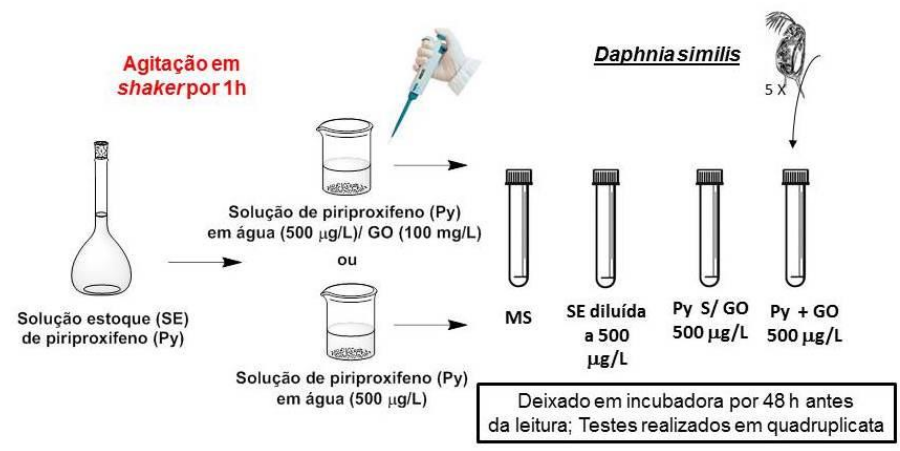

A concentração de piriproxifeno nos béqueres foi de 500 $\mu \mathrm{g} / \mathrm{L}$. A solubilidade do piriproxifeno em água é aproximadamente $370 \mu \mathrm{g} / \mathrm{L}$. Após 1 hora de agitação, alíquotas dos sistemas foram tomadas e submetidas aos testes de toxicidade aguda com $D$. similis. Quando o GO não estava presente, houve baixa mortalidade (20\%). Este resultado indicou que o agrotóxico não foi solúvel nesta concentração e, portanto, não foi tóxico para os microrganismos. Por outro lado, na presença do GO, foi verificada uma alta taxa de mortalidade, cerca de $80 \%$, indicando que o GO atuou como surfactante, aumentando a solubilidade, e consequentemente a toxicidade, do agrotóxico.

Tabela 1. Resultados dos testes de toxicidade.

\begin{tabular}{ccc}
\hline \multirow{2}{*}{ Amostra $\mu \mathrm{g} / \mathrm{L}$} & \multicolumn{2}{c}{ Imobilidade } \\
& Total & $\%$ \\
\hline Controle MS & $0 / 35$ & 0 \\
$\begin{array}{c}\text { SE }(500 \mu \mathrm{g} / \mathrm{L}) \mathrm{MS} \\
\text { Diretamente }\end{array}$ & $29 / 35$ & 82,9 \\
$\begin{array}{c}\text { Py (500 } \mu \mathrm{g} / \mathrm{L})+\mathrm{GO} \\
(\mathbf{1 0 0} \mathrm{mg} / \mathrm{L}) \text { agitação }\end{array}$ & $30 / 35$ & 85,71 \\
$\begin{array}{c}\text { Py (500 } \mu \mathrm{g} / \mathrm{L}) \\
\text { agitação }\end{array}$ & $8 / 35$ & 22,9 \\
\hline
\end{tabular}

\section{Conclusões}

O piriproxifeno foi purificado e utilizado no estudo que avaliou o comportamento deste agrotóxico frente ao nanomaterial GO. Os testes de toxicidade aguda indicaram que o GO aumentou a solubilidade do piriproxifeno em água, atuando com surfactante. O GO se apresenta como potencial agente surfactante sólido que pode ser removido facilmente após o uso, diferentemente dos surfactantes comercializados atualmente.

\section{Agradecimentos}

Processo FAPESP 2015/07033-7; CAPES; CNPq; FAEPEX; Laboratório de Química Orgânica e Materiais UNICAMP.

\footnotetext{
${ }^{1}$ https://nacoesunidas.org/uso-do-larvicida-pyriproxyfen-para-o-controle-domosquito-aedes-e-seguro-esclarece-oms/ (acessado em 09.07.2018)

2 Ncibi, M. C.; Gaspard, S.; Sillanpaa, M. J. Haz. Mat. 2015, 286, 195.

${ }^{3}$ Cote LJ, Kim J, Tung VC, Luo JY, Kim F, Huang JX (2011) Graphene oxide as surfactant sheets. Pure Appl Chem 83:95-110
} 